\title{
اللغة العربية قبل الإسلام
}

\author{
نور هدايات \\ مدرس قسم تدريس اللغة العربية في الجحامعة الإسلامية الحكومية بنجكولو \\ (البريد الإلكتروني: dayat38@yahoo.com)
}

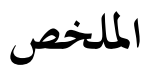

\begin{abstract}
Language is a set of words used by a group of people to express or reveal a purpose. Arabic is one of the Sam languages, Arab nation is a kind of Sam nations (identical to sam ibn nuh). As we all know that the Arabic language is not only used by the Arab nation, but also used in many nations of the world. Before the arrival of the Islamic religion in the Arab nation, the Arab nation lives in the Jahiliyyah. Arabic civilization before Islam in the social field has a bad social order, but in the field of arts and language is highly advanced. The Arabic language since its oldest era has been divided into many dialects that differ from each other in many aspects of Phonology, Semantic, Sintax, and Vocabulary.
\end{abstract}

Keyword: Arabic Language, Before, Islam

$$
\begin{aligned}
& \text { الإرث. في حين أن المتصاد } \\
& \text { المقدمة } \\
& \text { العرب تسمح الربا. } \\
& \text { حضارة العرب قبل الإسالام } \\
& \text { ان اللغة العربية منذ اقدم } \\
& \text { في الجمال ال[جتماعي سيئة للغاية. } \\
& \text { عصورها انقسمت الى لهجات كثيرة } \\
& \text { العرب الضرر المعنوي يحدث في } \\
& \text { يختلف بعضها عن بعض فن كثير } \\
& \text { جمموعة متنوعة من القضايا، مثل } \\
& \text { من مظاهر والصوت لـلة } \\
& \text { شرب الخمر، والزنا، ودفن البنات } \\
& \text { والقواعد والمفردات واختصمت كل } \\
& \text { أحياء، والرجال لديهم عادة الزواج } \\
& \text { قبيلة وكل جماعة متحدة فن ظروفها } \\
& \text { والطلاق في الإرادة، وجعل النساء } \\
& \text { الطبيعية والمجتماعية بلهجة من } \\
& \text { الأرامل من قبل زوجها باعتبارها }
\end{aligned}
$$$$
\text { هذه اللهجات غير انه قد اتيح }
$$ 
هذه اللهجات فرص كثيرة قبل مجيء الإسلام رِيْ خضم المجتمع للاحتكاك بفضل التجارة وتبادل العربي، والعرب يعيشون في الجاهلية. أهما

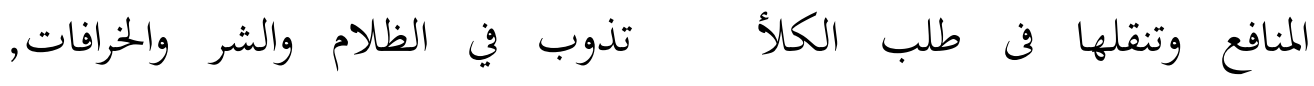
وبتمعها في الحج و والمواق فضلا عن ذلك، كان لديهم معرفة

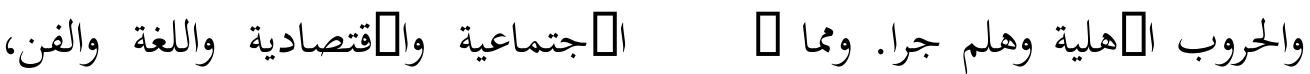

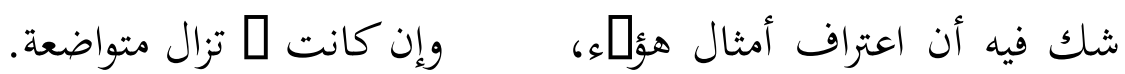

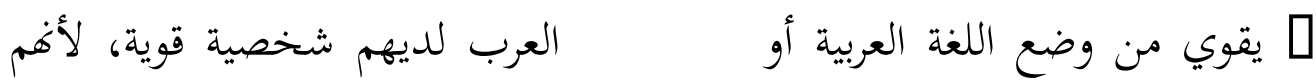

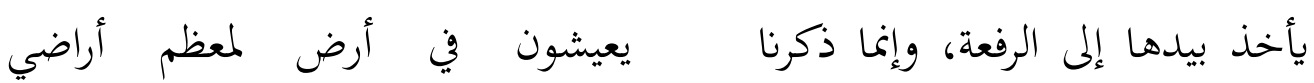

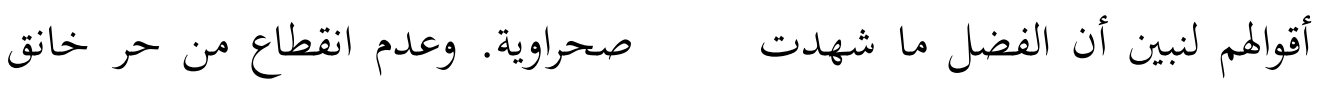

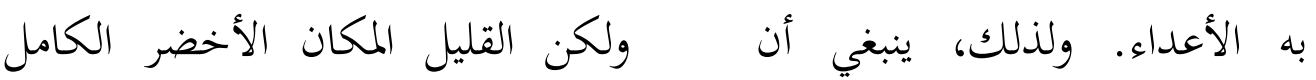
نعرف أحوال اللغة العربية قبل بجيئ من أشجار النخيل والمياه التي تكون

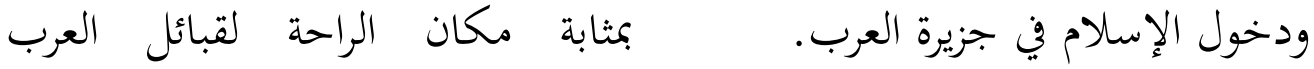
البدوية.

حضارة العرب قبل الإسلام في البمال المجتماعي سيئة للغاية. العرب أ. المياة العرب قبل الإسلام جزيرة العرب اسم يطلق على الضرر المعنوي يحدث في مجموعة متنوعة

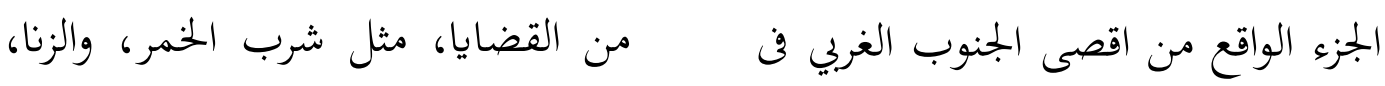

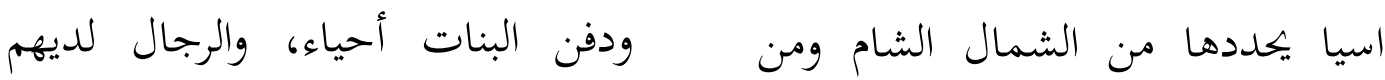

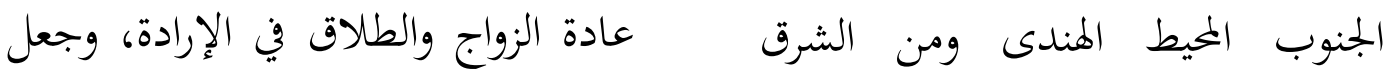
الخليج الفارسى ومن الغرب البحر النساء الأرامل من قبل زوجها باعتبارها

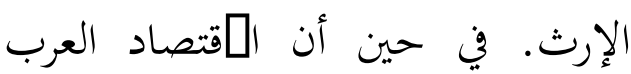
تسمح الربا. 
قبائلهم: طسم وجديس وعاد وعمود وعمليق وعبدضخم.

الثانية: العرب العاربة, وهم بنو قحطان الذين جعلوا عن سقي الفرات, واختارو اليمن منازل لهم, وامتزجت لغتهم بلغة سبقيهم, ثتم انتشرت فن انحاء الجزيرة, ومن امهات قبائلهم: كهالان وحمير. الثالثة: العرب العرب المستعربة, وهم بنو اسماعيل الطارئون على القحطانين, والممتزجون بهم لغة ونسبا والمعروفون بعد بالعدنين. ومن أمهات قبائلهم: بيعة ومضر وأياد وانمار '2

\section{ج. أصل اللغة العربية}

اللغة العربية هي احدي

اللغات السامية, والعرب من الجنس الجسيت السامي (نسبة الى السام بن نوح) الذى كان يسكن الفرات او بين غرين وحينما ضاقت به البلاد تفرقت فروعه في انحاء المارض, فنزل افرع العربي في الجزيرة التي نسبت اليهم. فلغتهم سامية وهي

\footnotetext{
الشيح امد المسكندرى و الشيح مصطفى عناني " الوسيط فن

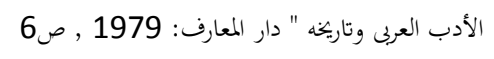

ووي ججال الفنون واللغة، وكان العرب في فترة ما قبل الإسالام متقدمة جدا. لغتهم هي جميلة جدا والشعرية لهم كثيرا. في حيهم شاعر يكظى باحترام كبير. للحفاظ على المنافسة بين الشعراء والقبائل العربية في كل عام عقد اجتماع عام في عكاظ. تلاوة الشعراء قصائدهم تتسابق بعضها البعض للحصول على الجائزة.

\section{ب.مفهوم اللغة العربية وعصورها} اللغة هي الفاظ يعبربها كل قوم عن اغراضهم, فاللغة العبية هي الفاظ يعبربها العرب عن اغراضهم. وامة العرب هم الذين كانوا يسكنون الجزيرة العربية وينطقون باللغة

$$
\text { وهم ثلاث طبية سليقة وطبعا. }
$$

الأولى: العرب البائدة, وهؤلهاء لم يصل

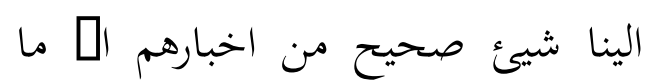
قصه الله علينا في القران الكريم, واله ما جاء في الحديث النبوي, ومن اشهر 
نمت تلك الفووع فانتشرت وتفرقت فن افاق الجزيرة ثم أثرت البيئات المختلفة على السنتها وطرأت عليها لهجات تختلف في كيفية النطق حينا. او او كاختلاط الملفاظ الدالة على مدلول واحد كالتردفات في مثل: (السد والليث والضيغم والضرغام والسبع)

\section{د. اختلاف لمجات العرب}

قدمنا ان المهة العربية تألفت

اخيرا من شعبين عظيمين: القحطانين

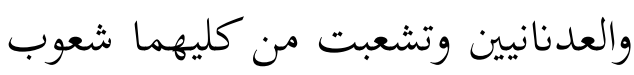
وقبائل لها لهجات مختلفة الفروع متحدة المصول غير ان لغة حمير من القحطانين غلبت على اخواتحا ثم دخل فيها من اللغة العدنانية الفاظ وأسالب اختلفت قلة وكثرة باختلاف لهجات, وعمرت حتى ظهورال[سلام وزالت بعده وبقيت منها الفاظ امتزجت بالعدنانية .

عرفنا ان اللغة العربية التى تزال تستخدم عند الهم العربية لغة

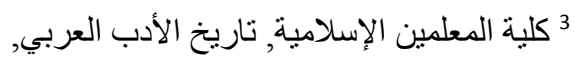
الجزء الأول. الطبيعة الجديدة, دار السلام. ص: 7
اقرب فروع السامية الى اصلها لأ ن العرب لم يختلط بغيرهم كاختلاط سواهم

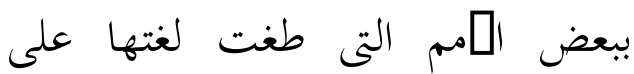
لغتهم لغتهم فأبعدةا عن اصلها. واللغة العربية هى لغة اسماعيل عليه السلام التى تكلم بها, وليست لغة ابيه ابراهيم لأن لغته كانت الكلدانية, ول لغة أمه لأنها كانت مصرية تتكلم العبرية. وللباحثين في لغة اسماعيل رأيان: المول: يقول أن اسماعيل تعلمها من رالن جرهم الثانية التى عاشت معه الى جانب زمزم فنشأ بينهم وتزوج منهم, وتعلم لغتهم - وجرهم هذه يمنيه من العمالقة الذين كانوا يعيشون فن اليمن. الثانى: يقول ان هذه اللغة يعرب من قحطان من العرب المتعربة اتى كانت

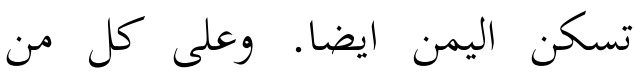
الرأيين نرى أن لغة اسماعيل وافدة من اليمن, وربما تكون فيها بعض الفاظ الكلدانية وربما تكون فيها بعض الفظ كلدانية اخذها عن ابيه وأخرى عبرية اخذها عن امه. وقد عاشت فروع معد وفروعه الحطانين في الجزيرة العربيةوثم 
ادب وكتابة وتأليف قد نشأت ببلاد لمجة من لهجاهما وهى لهجة قريش على نجد والحجاز. ثم انتشرت في كثير من اخواتما. المناطق التي كانت تشغلها من قبل

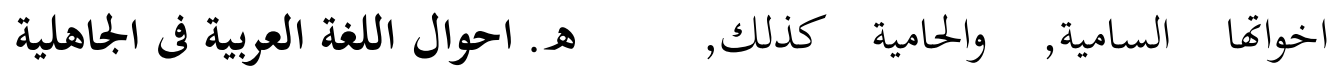
ان اللغة العربية منذ اقدم فنجدها يستتعملها الناس فن فلسطين عصورها انقسمت الى لهجات كثيرة والأردن وسوريا ولبنان والعراق والكويت ومصر والسودان وبلاد المغرب العربي. يختلف بعضها عن بعض في كثير من

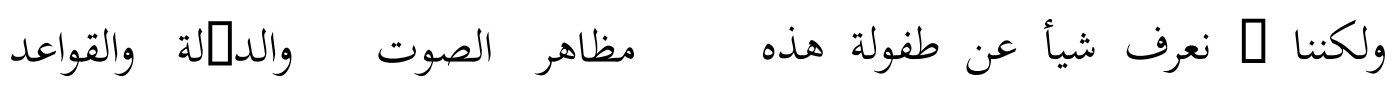
اللعة, اذ لم يعثر العلما ء في مواطنها والمفردات واختصمت كل قبيلة وكل

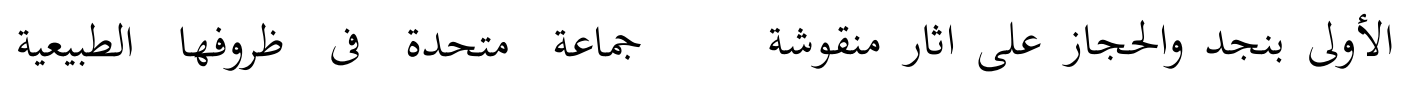
او مكثوبة تلقى ضؤا على حالتها والهتماعية بلهجة من هذه اللهجات غير انه قد اتيح هذه اللهجات فرص

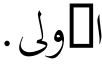
كثيرة للاحتكاك بفضل التجارة وتبادل واقدم ما وصل الينا من اثار هذه اللغة هو ما يعرف بالهدب الجاهلى المنافع وتنقلها في طلب الكلأ وبحمعها

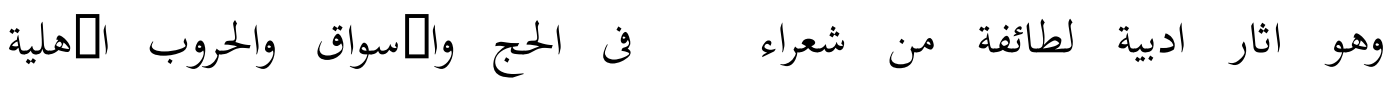

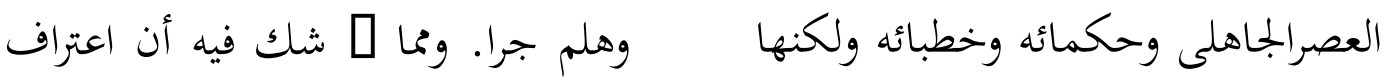

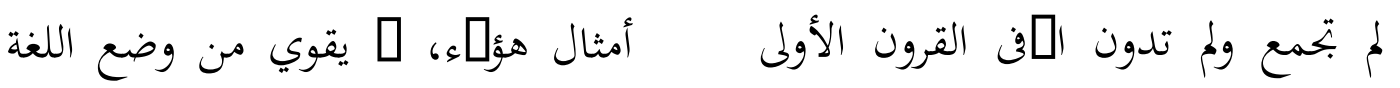
للعصر المسلامى. ويرجع تاريخ اقدمها العربية أو يأخذ بيدها إلى الرفعة، وإنما

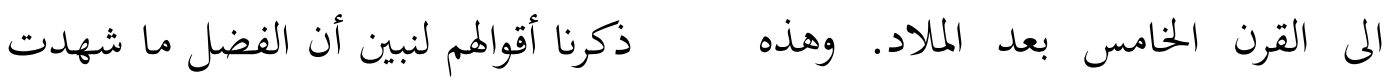

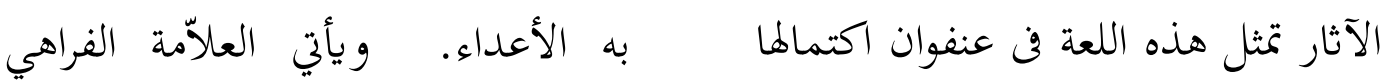
وعظمتها. بعد ان اجتازت مراحل كثيرة الهندي - -إمام العربية في عصره -ليقول

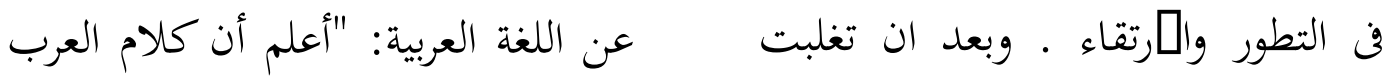
كله نمط أعلى من كلام الأمم الذي العربه 
اليها القرابين ,فكان لقريش بذلك سلطان ديني على القبائل العربية. 2. سلطان اقتصادي. فقد كان كبير من التجارة فن يد القرشيين الذين كانوا ينتقلون بتجارقم في مختلف بقاع الجزيرة العربية من الشام شنمال

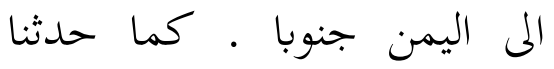
بذلك سورة قريش : لميلاف قريش الأية ( القريش : 1 ) وبفضل هذا النشاط اصبح زمام الثروة فن هذا البلاد في يد قريش . 3. نفوذ سياسي في سائر البلاد. فقد بلد تريس تحقق لقريش بفضلها نفوذها الديني والقتصادي وبضل موقع بلادها نفوذ سياسي قوي في سائر بلاد العرب في العصر الجاهلي 4. أن لهجة قريش كانت اوسع اللهجات العربية ثروة وارقاها

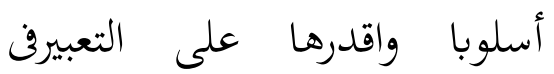
مختلف القول وكان ذلك بفضل ما اتيح [ملها من وسائل الثقافة وفرض كثيرة للا حتكاك بمختلف

$$
\text { اللهجات العربية }
$$

تعودت به، لأفم مولعون برزانة القول وهذيبه من أمور سخيفة، فهم يجردون كلامهم من كل رابطة، ولو فعلوا ذلك كان عاراً على السامع، فإنه يفهم الروابط بذكائه، فلذلك كثر فيهم

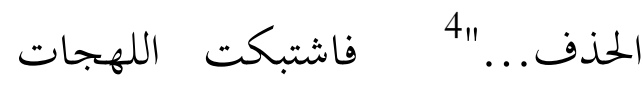
العربية بعضها مع بعض فن صراع لغوى , كتب النصر للهجة قريش فاستولت على جميع لهجات اخرى في المحادثة وفى ميادن ال]دب في مختلف القبائل العربية فاصبح العربي - ايا كانت قبيلته -

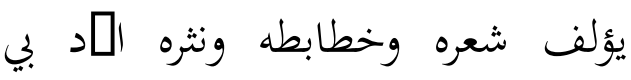
بلهجة قريش . بوسك وقد ساعد على تغلب هذه اللهجة عوامل كثيرة من اهمها ما يلي : 1. عامل ديني. قريش صاحب بيت الله, يقيمون حوله ويقومون بسدانته وكان البيت مقدسا فن نظر معظم القبائل العربية في الجاهلية , يحجون اليه ليؤدو

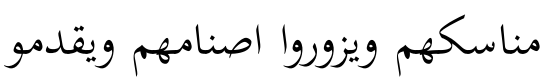
دلائل النظام (ط2، الدائرة الحمبدية الهندية: 1991م) ص 197 
صوات والقواعد والمالب وينقل

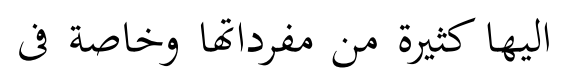
النواحى التى كانت تعوزها, فقويت لغة قريش بذلك مقوماتما, واتسع نطاقها وزادت مرونة وقدرة على التعبير عن مختلف فنون القول. غير اها لم تقف في لهن اقتباسها عند المور التى تعوزها بل انتقل اليها كذلك من هذه اللهجات كثير من المفردات والصيغ التى لم تكن فن حاجة اليها لوجود نظائرها في متنها الأصلى. 2. المجتمعات الخاصة التى اعتاد

العرب فن هذاالعصر ان يعقدوها

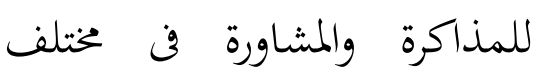
شؤوهم ال[جتماعية والفصل في الدعاوى والمنازعات, او للتحالف والتعاقد, او لمخض ال[نس وترويح النفس بذكر القصص والأخبار وكانت اللغة المستخدمة في هذه المجتمعات هى لغة قريش. 3. الأسواق : : كان للعرب عامة هيتئ للتجارة والأدب وغيرها, ال: لـكاد
وبعد ان تم للهجة قريش التغلب على اللهجات العربية المخرى, وبعد ان اصبحت لغة الـدب التبل لسائر قبائل العرب نزل القرأن بها فلا

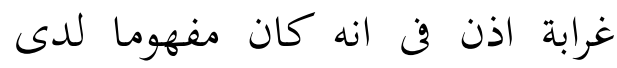
جميع القبائل. ول] غرابة كذلك ان جاءت اثارالجاهلي معلقاتما وشعرها وخطبها وحكمها وامثالها مؤلفة بلغة قريش.

\section{و. عوامل فضضة لغة قريش}

كانت هناك عوامل كثيرة

على النهوض بلغة قريش وتوسيع نطاق

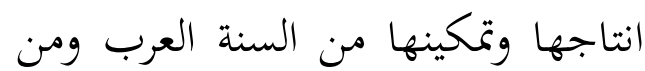
اهم هذه العوامل ما يلي :

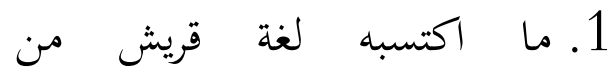

احتكاكها باللهجات العربية

الأخرى . فمن المقرر في قوانين اللغات ان اللغة المنتصرة [ـ تخرج سليمة من صراعها , بل ان طوال

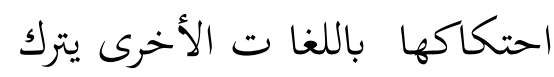

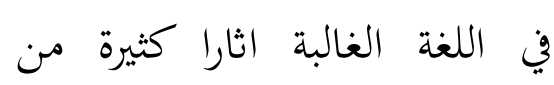
اللغات المغلوبة في نواحى الأ 
لـارتباد مواقع الغيث والكلأ وانتزاع ما يحتاجون اليه [منعامهم من غيرهم ويدفعهم الى ذلك المدافعة عن الوطن ضد المجنبي او الوفاء بالعهود وحماية

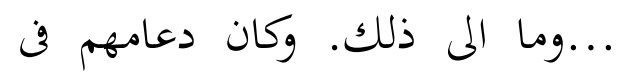
هذه الحروب الكلام البليغ يلجأ اليه قوادهم وسادتم وجنودهم للتفاخر والحث على والشماعة و والـقدام

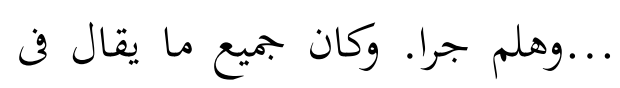
هذه الحروب مؤلفا باللغة التى كان

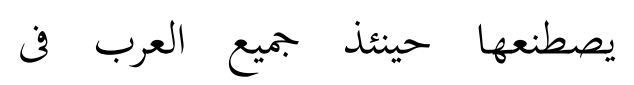
ميادين المدب, وهى لغة قريش. وكان لذلك من اثر في فضة هذه اللغة وبتحويدها واتساع نطاق ادابها.

\section{ز. عبارة اللغة فى الجاهلية}

تلخص احوال العبارة في الجاهلية فيما يأتى

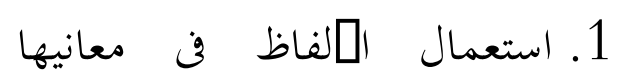
الوضعية , او فن معان مناسبة

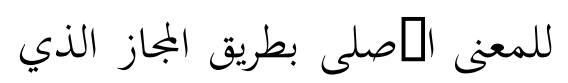
يصبح بعد غلبة المستعمال
يخلو منها شهر من شهور السنة . أشهرها : عكاظ والجمنة وذو المجاز

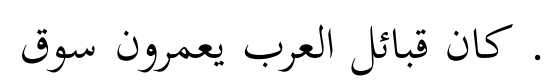
عكاظ فن العشرين من ذى الحجة الى ذي القعدة ثم يغادروها الى ذي المجنة قرب مكة فيقضون به بقية ذى القعدة ,ومنه يذهبون

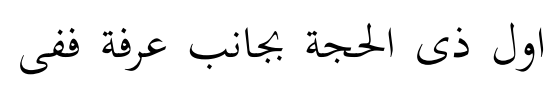
هذه الأسواق الثلاث وغيرها كان العرب يتبارون في اجادة القول خطابة وشعرا ونثرا ويتحاكمون في الخصومات اويتفاخرون بالهسان والحساب, و ويتفنون بالحب والجمال. وكان المتحار بالكالام فيها اعظم شأنا من ولخمال الجتحار بالبضائع · وكانت اللغة

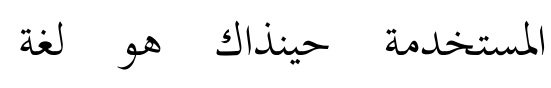
قريش. وال يخفى ما كان لذلك من اثر بليغ فن هضة هذه اللغة.

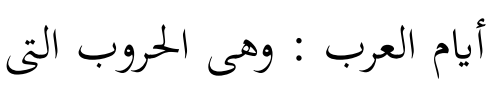

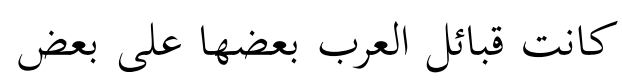
اوتشنها على الحجانب ـ وكان يدفعهم الى كثير منها نوع حياتم وايلافهم 
تكلف, وبدون مراعاة لما تستلزمه

الصناعة البديعية فلم يتعمد

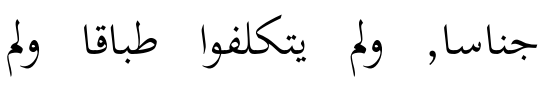

يقصدوا الى تورية وما وقع لهم من

المحسنات الكلامية, على قلته فانما كان عفوا [اتعمل فيه

خلا بعضا من سجع الكهان

5. خلو الكلام العربى من اللحن لأن

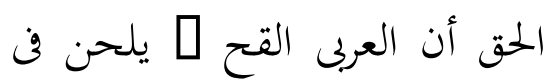

لغته .

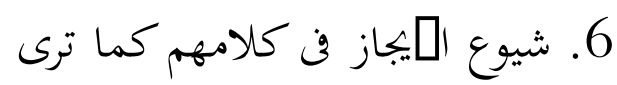

ذلك واضحا في نثرهم وشعرهم.
والف حقيقة جديدة ولذلك

يظهر لنا عند تلاوة الشعر العربى

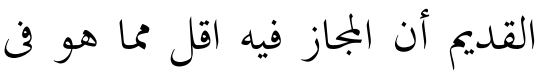

كلامنا, وانه قريب من الحقيقة

لشدة علاقته بالمعنى إلصلى

وارتقاء بعضه الى رتبة الحقيقة.

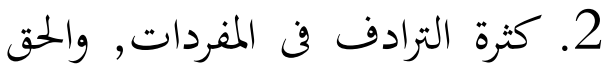

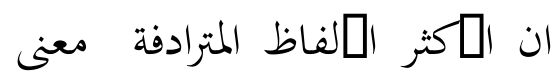

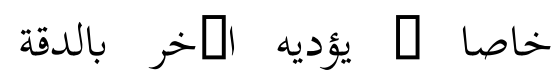

,وبعض المترادفات من اختلاف

اللغات القبائل الفصيحة اتي

جمعت لغاقا وتكون منها اللسان

العربى المروي لنا المحفوظ في كتب

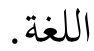

3. قلة ا[مجمي المعبر عنه بالمعرب,

على انه لم يقم اللى المن دليل

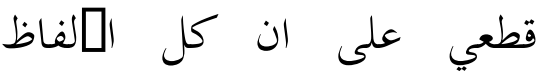

المشتركة بين لغة العرب ولغات

الأعاجم نقلها العرب عن غيرهم

ولمج ينقلها غيرهم عنهم حتى

يهكم بأها اعجمية [ عربية.

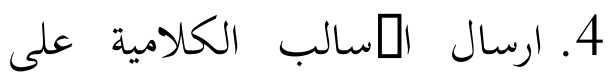

حسب ما تقتضيه البلاغة بدون 


\section{الخلاصة}

ان اللغة العربية منذ اقدم عصورها قدمنا ان المة العربية تألفت اخيرا من انقسمت الى لهجات كثيرة يختلف شعبين عظيمين: القحطانين والعدنانيين بعضها عن بعض فن كثير من مظاهر وتشعبت من كليهما شعوب وقبائل لها

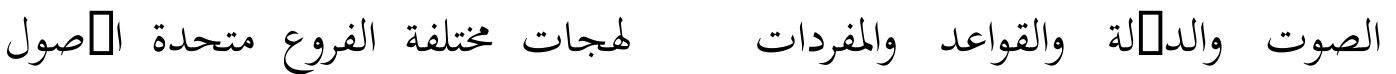
واختصمت كل قبيلة وكل جماعة متحدة غير ان لغة حمير من القحطانين غلبت

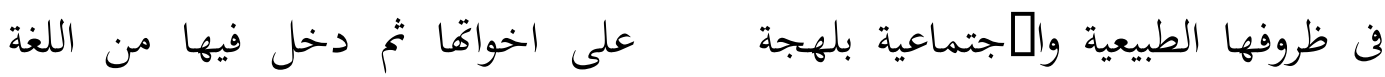

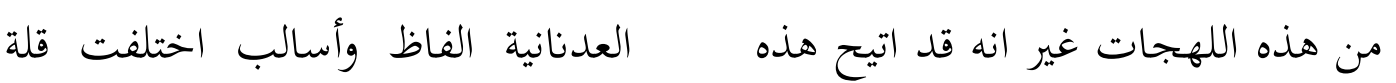
اللهجات فرص كثيرة للاحتكاك بفضل وكثرة باختلاف لهجات, وعمرت حتى لهن

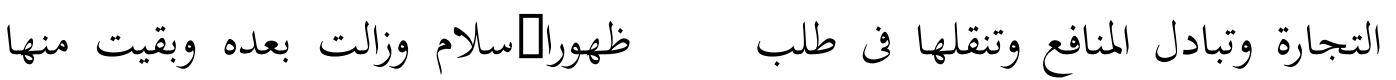

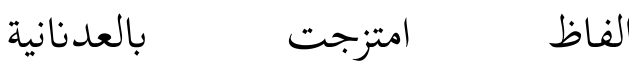
الكلأ وبحمعها في الحج والمسواق والحروب المهلية وهلم جرا.

زيدان, تاريح ادب اللغة العربية,

$$
\text { المراجع }
$$

بيروت: مكتبة البحوث

عبدالرحمنابن خلدون. الجزء المول.

$$
\text { والدراسات, } 1997
$$

احمد الهاثمى, جواهر البلاغة في المعانى وابيان وابديع, مكتبة دار احياء

مقدمة العلامة ابن خلدون .

تاريخ وحيد عصره العلامة.

$$
\text { دارالفكر }
$$

$$
\text { الكتب العربية, } 1960
$$

احمد ابو سعد, معجم التراكيب ابوالفرج الصفهاني, الأغانى, بيروت: دارالفكر 1407هـ. واعبارات المصطلاحيةالعربية, المساتذة بالأقطار العربية, المعجم في بيروت: دار العلم للملايين, الـدب العربى وتاريخه, القهرة: 
كلية المعلمين الإسلامية, تاريخ الأدب

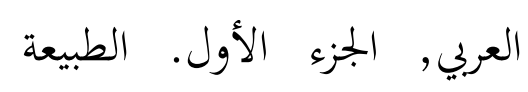

$$
\text { الجديدة, دارالسلام الحرئ }
$$

مُحُّيوسف, زهير ابن ابى سلمى حياته

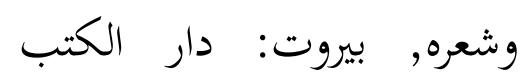

العلمية, 1411هـ

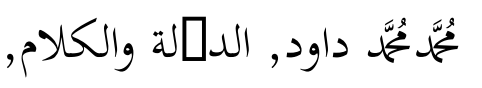

الشيخ أحمد الإسكندي والشيخ المصطفى عناني, الوسيط في

الأدب العربي و تاريخه, دار

$$
\text { المعارف, } 1978
$$

شوقى ضيف, الفن و مذاهبه فن النثر

$$
\text { العربى, القاهرة: دار المعارف فئ فاهن الثر }
$$

احمد ابن ابراهيم ابن المصطفى الهاشمى

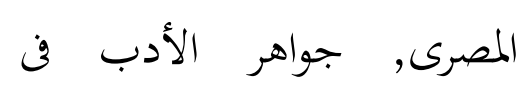

$$
\text { ادبيات وانشاء لغة العربية. }
$$

$$
\text { بيروت: دار الكتب العلمية. }
$$

البستانى, ادباء العرب في الجاهلية

وصدر المسلام, بيروت: دار الجاري

الجبل, وصلر 1989

الثعالبى, فقه اللغة وسر العربية,

القاهرة, 1938

الفاخوري, الموجز في الأدب العرى

وتاريخه, بيروت: دار الجلبل, الادبل

الطبعة الثانية, 1991 
